\title{
APORTACION AL TEMA DE LAS CONFISCACIONES EN EL REINO DE VALENCIA DURANTE LA GUERRA DE SUCESION*
}

\author{
Jesús PRADELLS NADAL \\ Universidad de Alicante
}

\begin{abstract}
Este trabajo resume la Memoria de Licenciatura que bajo la dirección de Enrique Giménez López fue defendida en la Facultad de Filosofía y Letras de la Universidad de Alicante en noviembre de 1982, con el título: "La Guerra de Sucesión: aportación al tema de las confiscaciones en el Reino de Valencia».
\end{abstract}

Para los reinos de la Corona de Aragón, y de manera muy concreta para el de Valencia, la Guerra de Sucesión tiene un significado especial en cuanto supuso la abolición de sus tradicionales instituciones forales. Tema éste que, junto al de si hubo o no rebelión que justificara la medida borbónica, se constituyó en centro de atención de la historiografía decimonónica(1). Los trabajos más recientes intentan proporcionar interpretaciones de conjunto sobre la guerra y sus consecuencias. Para Reglá significaría una nueva fase en el movimiento pendular del dualismo valenciano(2). Para Carmen Pérez es fundamental el conflicto internacional que surge con el problema sucesorio y que, al interiorizarse, se convierte en una guerra social y civil, pivotando en torno a tres puntos básicos: xenofobia antifrancesa, movimientos antiseñoriales y, sobre todo, defensa del status quo alcanzado durante el reinado de Carlos II y que Reglá acuñó con el término de neoforalismo (3). Para Kamen es fundamental el elemento antiseñorial, 
alimentado y utilizado por los aliados, a la vez que destaca el elemento militar como determinante en la adhesión de algunas zonas del País Valenciano a uno u otro de los bandos(4). En otra reciente obra reflexiona este autor sobre la necesidad de centrarse en los universos comarcales para explicar muchos aspectos de la España del Antiguo Régimen y expresa la conveniencia de revisar la perspectiva adoptada en su tesis doctoral (5). El tema se ha tratado también desde concepciones más globalizadoras, como en el caso de Pedro Ruiz que ve en la guerra, y en la división producida en los estamentos sociales, una cuestión interna que enfrenta dos concepciones o formas de entender el desarrollo del feudalismo y de la salida de su crisis. En definitiva, el enfrentamiento entre el modelo castellano, finalmente triunfador, y el modelo de la Corona de Aragón(6).

Sin embargo, son escasos los trabajos monográficos sobre aspectos concretos de la Guerra de Sucesión en el Pais Valenciano. Desde esta perspectiva abordamos el estudio de las características de la guerra y del proceso confiscador consiguiente en una de las unidades jurisdiccionales del Antiguo Régimen: la Gobernación de Alicante(7). La necesidad de establecer paralelismos que hicieran comprensibles los resultados llevó aparejada la labor de intentar trazar un cuadro general de las confiscaciones a nivel del Reino, así como del tratamiento que recibió el tema en los organismos de poder. Ni las fundamentales obras de Miñana, Belando, San Felipe, Ortí, Perales o Feliú de la Peña(8), ni las de autores más recientes, se refieren, salvo para anunciarlo, al problema de las confiscaciones. Tan sólo Kamen valora, de forma acertada en sus conclusiones generales, el alcance y características de las confiscaciones tanto en Castilla como en Aragón y Valencia. No obstante, el carácter amplio de su obra, centrada sobre todo en los aspectos de reforma fiscal tras los decretos de Nueva Planta, hace posible la introducción de matizaciones. La tesis de licenciatura elaborada no pretende ser un estudio exhaustivo de las confiscaciones, sino una aproximación que permita valorar de manera documentada el alcance de la represión en la posguerra, e incluso, el grado de participación de los diferentes estamentos en uno u otro bando, mediante las listas de confiscados y las de aquellos que justificaron su fidelidad a Felipe V.

\section{I.-Confiscaciones en Valencia: La obra de Macanaz}

Para determinar el volumen y caracteristicas de las confiscaciones en Valencia utilizamos las escasas referencias bibliográficas contenidas en las obras citadas, así como la documentación utilizada por Kamen, ya que la amplitud del tema le hizo optar por trabajar con los resúmenes documentales que hemos procurado detallar y cumplimentar con otras informaciones procedentes del A. H.N. 
En principio, las confiscaciones pueden ser consideradas como una más de las medidas globales de represión adoptadas durante la guerra y la posguerra. Tras la entrada en Valencia de las tropas borbónicas y la anulación de las medidas de tolerancia tomadas unilateralmente por el duque de Orleáns(9), el desarme de la población se convertía en medida prioritaria. Si se unen los decretos de Nueva Planta(10), el desarme, a excepción de los destacados partidarios de Felipe(11), la impopular y gravosa obligación de dar alojamiento a las tropas(12) y las imposiciones extraordinarias(13), no es difícil trazar un cuadro del descontento de la población(14). Con anterioridad a la batalla de Almansa, una Real Provisión de marzo de 1706 disponía el embargo de los bienes de los catalanes y valencianos rebeldes(15). Catorce meses después se ordenaba la formación de una Junta de Confiscaciones compuesta por cuatro ministros de la Audiencia(16). La medida no fue realmente efectiva hasta el nombramiento de Macanaz como Juez de Confiscaciones cuatro meses más tarde de su entrada en Valencia(17). En junio de 1708 Macanaz daba cuenta de sus actividades en tres memoriales. El primero se refiere a las haciendas reintegradas a los antiguos habitantes de Játiva, incluyendo compensaciones por los daños causados por la destrucción de la ciudad(18). Asciende la cantidad global a 1.184.998 libras valencianas en concepto de haciendas más 156.124 libras para la reparación de las pérdidas. Las devoluciones afectaron a más de ciento noventa individuos, de los que sólo uno es reseñado con título nobiliario, y alrededor de un $20 \%$ anteponen el Don.

Un segundo informe trata de las mercedes concedidas por el monarca en dinero, distinguiendo el funcionario detalladamente entre temporales y vitalicias. Hasta junio se habían librado 115.390 libras o pesos en dinero, casas, tierras y libramientos sobre créditos líquidos correspondientes a mercedes no recurrentes, quedando por satisfacer 25.737 pesos. De rentas perpetuas y vitalicias habían sido concedidas por la Corona mercedes por una renta de 56.455 pesos anuales, de los que, advertia Macanaz, "hay aún que consignar cantidad, pero se podian asignar acabando de liquidar las rentas...."(19). Las concesiones de cantidades por una vez afectaban a instituciones religiosas (aparecen cinco conventos de monjas con un total de 8.700 pesos, el Colegio de Predicadores de Orihuela, que recibe 1.000, dos frailes dominicos con 200 libras y 2.750 para el Obispo Auxiliar de Valencia); instituciones y cargos burocráticos (el Consejo Real de Castilla, 6.000 pesos; el Hospital General de Valencia, 12.000; a los oficiales de la Chancillería, 4.459; la Inquisición de Valencia, una renta anual de 3.400 libras, y otra de 23.000 libras anuales al Hospital de Inválidos de San Felipe; la villa de Yecla, una compensación de 3.000 , y tan sólo 500 la de Chiva). De los catorce sujetos que en la documentación aparecen reseñados por su título, tan sólo a dos no se les asignan rentas sino cantidades por una vez: al Marqués del Bosch y al Conde de Albalat, con 4.000 y 873 libras respectivamente. Las demás concesiones oscilan entre las 750 
libras anuales al Marqués de Centelles, las 1.000 del de Albaida, las 5.000 del de Castelar o la ya muy extraordinaria de 9.000 al Marqués de Sarno. Aparecen también veinticinco nombres correspondiéndoles asignaciones de dinero entre los 200 y los 1.000 pesos. Sobresalen por su cuantia las de don Carlos Carrafa, de 15.000, o la de don Antonio Montolíu, con 25.000 libras y una renta anual de 1.000. De estos veinticinco, tan sólo cuatro, incluido Carrafa, recibieron rentas por un total de 3.160 libras anuales.

El tercer memorial corresponde a las mercedes concedidas en tierras entre enero y junio de ese año(20). El total de las concesiones importaba 1.003 .890 pesos. Kamen señala que: «Desde el 18 de enero al 13 de junio de 1708 la Corona redistribuyó tierras por valor de 15.058 .350 reales en Valencias(21). Lo cierto es que por esas fechas sólo se habían podido librar 584.815 pesos, es decir, el $58,25 \%$ de las concesiones. La mayor cantidad corresponde a la nación francesa con 137.500 libras, todavia sin pagar, en remuneración de sus pérdidas. Sin duda, fueron destinadas a los franceses acomodados, tanto por la obligatoriedad de las justificaciones como por un memorial que los upobres y viudas» de esta nacionalidad elevaron al Consejo exponiendo su precaria situación y afirmando que, de los bienes confiscados en Alicante, sobraban 130.000 pesos(22). Suposición muy alejada de las cifras reales como pudimos comprobar. Por lo general, las tierras fueron concedidas a nobles titulados y militares destacados por sus servicios, asi como a viudas de oficiales. De los sesenta y cuatro nombres de la lista, sólo once lo son por su título, predominando los italianos. Oscilan las cantidades entre las 27.500 y las 10.000 libras, estando casi en sus tres cuartas partes por satisfacer. Otros cuarenta y un individuos aparecen relacionados por sus nombres, aunque algunos ostentaban título nobiliario. Sobresalen las concesiones de don Tomás del Burgo, 43.385 libras; Francisco Caetano y Aragón, con 16.500, o la del propio Macanaz, con 20.625 libras; el brigadier Patricio Laules, con 22.000, etc. De éstos, veintiún individuos no habian recibido por esas fechas ni un solo sueldo. Sí, en cambio, las doce señoras y viudas que comprende la lista.

En unos momentos en que los gastos de la guerra exigían crear toda clase de arbitrios, las mercedes y concesiones no se libraron de los impuestos ordinarios ni de los extraordinarios. Según unas anotaciones que el Marqués de Mejorada acostumbraba hacer en pequeñas tiras de papel que intercalaba en los documentos de trabajo, "... las merzedes, $\delta$ donaciones perpetuas de bienes, propiedades $\delta$ rentas de concesiones de feudo, establecimiento de instituciones graciosas, y de bienes confiscados se lleva de sello a razón de tres sueldos por libra de lo que valiese la propiedad»(23). Por otra parte, la media annata se refundia en el sello(24). Seria en 1709 cuando entraran en vigor las medidas extraordinarias mediante un R. D. que disponía el valimiento del $80 \%$ de los frutos de las tierras concedidas(25), que posteriormente seria rebajado hasta el $60 \%, y$ 
su producto ingresado en el Tesoro de Guerra(26). Pero su aplicación no fue general, ya que, por ejemplo, se suspendió para el caso alicantino en consideración a los daños causados por la guerra(27).

Cuando Macanaz abandonó Valencia, la administración de las confiscaciones pasó a manos de la Superintendencia General de Rentas. A instancias del Consejo de Hacienda, se elaboraron informes completos sobre el estado de los bienes que aún quedaban en la administración real(28). En total, la cantidad esperada para 1713 era de 149.498 pesos, 14 sueldos y 5 dineros, de los que habría que descontar en concepto de cargas y obligaciones de justicia 103.158 pesos. Valorar el volumen de las confiscaciones a partir de la utilización de los datos del informe puede distorsionar su alcance. Así, por ejemplo, se resumía que los bienes conjuntos de Orihuela y Alicante producían 1.133 libras, 14 sueldos y 5 dineros anuales. Después de analizar el caso alicantino y, en especial, la administración que la ciudad hizo de los bienes que le fueron concedidos, aparece como evidente que muchos de los bienes no rentaban por esas fechas, al no haber sido arrendados. Sobre todo, en el caso de la propiedad urbana, deteriorada por la guerra u ocupada por funcionarios reales y militares. Con el tiempo, estos bienes se incorporaron al mercado de arriendos, superando, incluso, el valor de los arriendos de los bienes rústicos.

El detallado informe de Pedrajas se dividia en varios apartados:

1. ${ }^{\circ}$ Bienes confiscados en Valencia sujetos a cargas. Aparecen los restos de las propiedades de siete nobles que trataremos más adelante, comparativamente con los aristócratas castellanos y aragoneses. Igualmente se reflejan propiedades de miembros de la nobleza no titulada valenciana, totalizando unos ingresos netos para la Hacienda de 1.170 libras, 6 sueldos y 10 dineros. Gran parte del producto quedaba consumido por las cargas propias o por las asignadas judicialmente. Las partidas del activo se componen frecuentemente del arriendo de derechos señoriales, propiedades rústicas, urbanas y censos muy depreciados. Podemos citar el caso de don Luis Esplugues y March, al que le fueron confiscados los derechos señoriales de Puebla Larga, arrendados por 1.125 libras y con unas cargas, reducidas para la media, de 206 libras; o el de don Francisco Carrós, al que le fue confiscada la baronía de Jorga, arrendada en 400 libras, y de las que 300 estaban asignadas a la satisfacción de una merced en dinero y 80 más en concepto de alimentos para su hijo. En total, aparecen doce titulares de propiedades, de los que seis llevan el prefijo de Don, poco indicativo por otra parte, ya que su utilización en la documentación dista de ser sistemática. Calibrando por el nivel de rentas o el valor de las propiedades, puede decirse que, en general, los que aparecen son hombres acomodados, como Basilio Mancebón, que obtenía rentas de 205 pesos procedentes de una alquería y una casa, o José Madal, propietario de tres casas de Valencia, o José Vicente Torres, con una heredad arrendada por la Hacienda en 405 libras anuales. 
Los apartados $2 .^{\circ}, 3 .^{\circ}$ y $4 .^{\circ}$ del informe de Pedrajas se refieren a una serie de bienes muy corta, comprendiendo aquellos de los que nos constan cargas, bienes de eclesiásticos y bienes que no producen ingresos al Tesoro.

El apartado $5 .^{\circ}$ es mucho más significativo, ya que trata de los Bienes de Diferentes Parajes. Kamen, al referirse al alcance de las confiscaciones, escribe que: "Las listas completas de confiscación en Valencia, de 1713 , indican que en distintos lugares de la región fueron castigadas hasta cien personas con la pérdida de todas o parte de sus propiedades, por valor de 14.498 libras $14 \mathrm{~s} .5 \mathrm{~d}$. bruto y 4.340 libras $15 \mathrm{~s}$. $11 \mathrm{~d}$. neto» (34). Como decíamos, no se trata de todas las confiscaciones, sino de aquellas que quedaban en manos de la Hacienda. Así, y por referirnos a centros urbanos que estuvieron en manos aliadas, de Villajoyosa se estima un valor bruto de 1.400 libras y una renta de 56 libras. Ni las confiscaciones pudieron ser exclusivamente urbanas, ni la renta es proporcionada al alcance de la confiscación. La desproporción se debe a que esas casas estaban "casi todas derruidas" (30). De cuatro vecinos de Cullera se consideraba una renta de 47 libras y 2 sueldos. La referencia al número de afectados por las confiscaciones es notablemente corta, ya que, sólo en Alicante, se contabilizan 165 confiscados en 1709. Solamente con la localización de los autos originales de confiscación, o documentación complementaria, será posible conocer la distribución social de las confiscaciones y su alcance, con las consecuencias que implica. El caso más claro de todos para poner de relieve la dificultad de establecer su alcance a través de los ingresos para la Real Hacienda es el de Denia. Pedrajas explicaba en su informe que: «De vecinos que fueron de Denia (hay) casas y tierras por 124.361 libras y renta de $800 .$. (pero) se previene ser tan corto este producto respecto de su capital, por no haver havido, ni haver vezinos en Denia, que cultiven las tierras confiscadas, desde la recuperación de aquella plaza, en que se fue la mayor parte, $y$ asta todas las Religiosas de un convento, a los Enemigos, por cuyo motivo ha sido preciso dar a precios muy baxos los pocos pedazos de tierra, que se han arrendado este año...", quedando aún que satisfacer las cargas.

\section{II.-Confiscaciones e inmunidad eclesiástica.}

Los problemas en torno a las confiscaciones entre la Corona y la jerarquía eclesiástica, después que Felipe $V$ reconociera la inocencia como institución de la Iglesia y respetara los compromisos adquiridos con la Santa Sede(32), surgirán de forma especialmente violenta a raíz del caso de Játiva(33). El conflicto tiene origen en la doble circunstancia que hizo recaer en Macanaz los cargos de Juez de Confiscaciones y Reconstructor de San Felipe. En virtud de un decreto de 29 de junio de 1707 se disponía la transformación de la Audiencia según el modelo de las Chancillerias cas- 
tellanas, con la sola excepción de las cuestiones relacionadas con la Iglesia(34). Macanaz no podía ocuparse de los bienes de la Iglesia. Por otra parte, el texto para la reedificación de Játiva (35) disponia que no fuera admitida persona alguna, seglar ni eclesiástica, tachada con el crimen de infidelidad. Amparándose en esta disposición, Macanaz emplazó también a los clérigos y religiosos de Játiva a demostrar su fidelidad, asi como las rentas y propiedades que gozaban (36). El Capítulo valenciano y luego el Arzobispo, a través del Nuncio, elevaron sus quejas al Consejo de Castilla. Por medio de Curiel, y alegando la necesidad de mantener buenas relaciones con Roma, se exigía moderación a don Melchor y se le pedía que se pusiera bajo el control del Presidente de la Chancilleria.

La decisión del monarca de que las cuestiones de dependencia eclesiástica fueran resueltas por el Arzobispo no zanjó - posiblemente con conocimiento de causa - la polémica, ya que ni Macanaz, ni Grimaldo, consideraban la fidelidad debida al soberano como una cuestión de competencia eclesiástica(37). Gaite destaca también la voluntad secularizadora del ministro castellano dando prioridad, tal y como disponía el decreto de reconstrucción, a los asuntos civiles sobre los eclesiásticos y consideraba que, con los veinticinco clérigos que habian sido reconocidos como fieles por su juzgado, habia más que suficiente para la atención espiritual de la nueva comunidad (38).

Las quejas del clero se refieren a la carestia de los procedimientos del Juzgado de Macanaz, donde eran obligados a utilizar papel sellado; la escasa atención a la reconstrucción de iglesias y conventos, y disconformidad con el modo de hacerse los repartimientos de tierra. Según los informes de éstos (39), don Rafael había redistribuido tierras a unos doscientos vecinos, de los que setenta serian de la misma Játiva, diez forasteros y los restantes oficiales y labradores. El problema, según los clérigos, era que no se habian reconocido las obligaciones censales que a favor de las iglesias tenian cargadas. Aunque no se ha localizado la documentación original de Macanaz ${ }^{(40)}$, y sobre la base del contenido de los decretos, así como del análisis del proceso en Alicante, todo parece indicar que las quejas, especialmente sobre la ilegitimidad de la anulación de los censos, carecen de fundamento. Las quejas presentan los censos no reconocidos como propiedad de la Iglesia, cuando en realidad parecen ser censos respondidos a los clérigos como particulares. Asi, pues, el reconocimiento requería la demostración de fidelidad y de posesión, misión que Macanaz no estaba dispuesto a que se arrogase el Arzobispo. Entre 1708 y 1710, en que el Arzobispo se pasó al bando austracista, tienen lugar diversas peripecias que Martín Gaite examinó con detalle(41). Sin embargo, Macanaz ya había moderado el bando que dio origen al enfrentamiento ante las ordenes expresas de Madrid(42). 


\section{III.-Confiscaciones a la nobleza.}

Domínguez señala cómo durante el siglo XVII tiene lugar un proceso de aristocratización del poder basado en el predominio de un centenar de casas de Castilla(43). La instauración borbónica supondrá una reorientación de las líneas políticas, teniendo como principales objetivos la reforma del aparato estatal, el reforzamiento de las regalías frente a la Santa Sede y un creciente intervencionismo económico. Si nos centramos en el primer aspecto, se distingue claramente una doble dirección: la reorganización a nivel constitucional, que supone la abolición de los Fueros, y la intención de racionalizar la administración. Racionalización que pasará por dotar de mayor poder ejecutivo - de facto- a las Secretarías en detrimento de los Consejos, por la introducción de manteístas en los más altos puestos de gobierno y, claro está, el alejamiento de los núcleos de decisión política de los miembros de la alta aristocracia. También las necesidades de la guerra obligaban a otorgar los puestos de mando en función de la capacidad, más que por el lustre familiar(44). Aunque no se produce una reacción como estamento de la alta aristocracia, sí es posible detectar líneas de oposición a la política borbónica, rastreable en las conspiraciones de los primeros años y en las defecciones de personajes ilustres, generalmente, muy vinculados a la política austríaca durante los últimos años de Carlos II(45). A partir de 1706, atenazada Castilla entre Portugal y la Corona de Aragón, los motivos de resentimiento personal se convierten en razones estratégicas, de la misma manera que, en 1710, con la segunda entrada de las armas aliadas en Madrid, se produciră una oleada de desafecciones (46).

Las confiscaciones aparecen, pues, como un instrumento capaz de afirmar las regalías de la Corona sobre los privilegios nobiliarios y como una fuente de ingresos en un doble sentido: primero, como productoras de ingresos líquidos; segundo, y de hecho más importante, como una forma barata de remunerar con ellas a los fieles servidores de la dinastía.

Partiendo de esta situación, no es de extrañar el mayor volumen comparativo de las confiscaciones a la nobleza castellana que a la de los reinos forales, sobre todo si se tiene en cuenta el carácter que en un primer momento adquirió la lucha en Aragón y Valencia. Centrándonos en el caso valenciano, donde las primeras manifestaciones revisten un claro contenido antiseñorial (47), y las fuerzas aliadas toman como punta de lanza las formaciones campesinas, es fácil suponer por qué la nobleza valenciana se inclinó hacia lo que, en aquellos momentos, aparecía como el partido del orden. Como escribe Miñana: "Temían no sucediese en aquel levantamiento lo que suele suceder en los motines del populacho, que no se apagan fácilmente sino con la muerte de los nobles y a (sic) confiscación de sus bieness (48).

La participación de la nobleza titulada en el bando austracista es muy 
reducida, destacando en los primeros momentos Cardona, el Conde de Carlet y el Duque de Mirasol. En 1706, cuando el destino de la monarquia parecia decantarse a favor de Carlos, se produjeron las defecciones más sonadas y numerosas: el Marqués de la Casta, el Conde de Sirat, el de Villafranqueza, el Conde de Casal o el Marqués de Rafal. Las listas de 1713 recogen parte de los bienes que les fueron confiscados ${ }^{(49)}$. Destacan, por lo general, las grandes sumas con que estaban cargados sus patrimonios. Por otra parte, las obligaciones de justicia dejan muy mermados los beneficios para la Hacienda Real. Las noticias del Superintendente nos permiten conocer las partidas del activo y del pasivo de muchos de los confiscados. El primero se compone de uno o varios lugares de señorio, propiedades en la huerta valenciana, urbanas y gran cantidad de capital censal. La partida del pasivo comprende, después de pasar por el tribunal de confiscación, de alimentos temporales para uel mantenimiento y decoro" de los miembros inocentes de la familia afectada; dotes de herencia y subsistencia perpetua; censos perpetuos; patronatos y fundaciones. Como señalamos, estas listas no recogen la totalidad de las propiedades de los desafectos, ya que, en ocasiones, sus dominios quedaban fuera de la jurisdicción de la Superintendencia. Así en el caso del conde de Villafranqueza, el informe de Pedrajas se refiere a las propiedades valencianas, que incluyen un señorío, con un saldo para el Tesoro de 177 libras y 2 dineros. Pero, además, habría que contabilizar sus posesiones en Alicante, estimadas por el Juez de Confiscaciones en un total de $\mathbf{5 5 . 5 8 3}$ libras, de las que aproximadamente la mitad correspondían al capital censal(50), pudiéndose estimar su renta global en alrededor de las mil libras anuales.

\section{IV.-La política cortesana.}

La política de Felipe $V$ no pasó por proponerse reformas sociales más allá de permitir el acceso de manteístas a algunos de los puestos de mayor relevancia en el aparato estatal. El proceso de reformas a las que nos referimos distó mucho de ser unitario. Tampoco respondía a un plan trazado con anterioridad y, en muchos casos, se hizo de manera improvisada ante los acontecimientos de la guerra. En torno al monarca se daria la lucha entre las posiciones reformistas, representadas por el llamado partido francés y sus acólitos españoles - no siempre dispuestos a satisfacer sus peticiones (51) - y las posiciones conservadoras representadas por el Consejo de Castilla(52). Enfrentamiento que se va a producir prácticamente en todas las cuestiones fundamentales, bien en el fondo, bien, en la forma de ejecución. Así, en el tema de la reforma de los órganos gubernamentales, en el de las regalias frente a la inmunidad, respecto al papel de los Colegios Mayores y sus relaciones con el Consejo, y, en definitiva, muy imbricado con los anteriores temas, también en el de las confiscaciones. 
Los prototipos de las posiciones extremas serian Macanaz y el por entonces Fiscal Curiel. Los planteamientos de Macanaz se basan en la utilización de la autoridad del monarca para fortalecer sus regalías frente a la Iglesia, pero también frente a cualquier estamento. Sus escritos sobre confiscaciones giran contra la alta aristocracia al defender la reintegración de los patrimonios nobiliarios a la Corona. El argumento principal no es sino una hipotética monarquía goda donde todos los poderes emanaron del rey por vía de concesión(53). Se trata, en resumen, de crear una nobleza de servicio basada en el mérito, frente a la nobleza decadente basada en el privilegio de sangre. Por su parte, don Luis Curiel defenderá a capa y espada los tradicionales privilegios de la aristocracia, basados en última instancia en la vinculación y el mayorazgo, inalterables por encima de la autoridad del rey, tal y como sancionaba la legalidad vigente a través de las cláusulas de fundación. Defiende la confiscabilidad temporal, pero respetando siempre la vinculación a la familia de forma que, a la muerte del desafecto, los patrimonios pasasen íntegramente al sucesor legal. La Corona siguió una conducta híbrida entre ambos extremos, aunque optando de forma global por el segundo, sobre todo tras el matrimonio con Isabel y el giro de la política nacional(54).

\section{V.-El proceso confiscador en Alicante.}

El estudio del proceso confiscador en la Gobernación de Alicante, dentro del marco de las características que en este área tuvo la Guerra de Sucesión, constituye el núcleo fundamental de nuestra tesis de licenciatura. Se trata de conocer el proceso legal, los bienes implicados, su carácter, la procedencia según grupos sociales, su destino y, en el caso de los adjudicados a la ciudad, también de su administración, como una partida más de las rentas municipales.

Dentro de las competencias de Macanaz como Juez de Confiscaciones para el Reino de Valencia estaba la de nombrar subdelegados para las diferentes partes del Reino. Poco después de ser recuperada la plaza alicantina por las armas borbónicas, don Rafael pasó a hacerse cargo de algunos efectos en nombre de la Real Hacienda. Con ese motivo escribia a Grimaldo el 9 de diciembre, trazando un breve panorama de los daños causados por la guerra. Informaba de la destrucción, del éxodo de la población y daba noticia de haberse dedicado al acopio de granos, harina, aceite y otros útiles, "lo que en medio del exercito no es poco trabajo»(55). Con anterioridad habia nombrado un Comisario Delegado de Confiscaciones para las Fronteras de Castilla y Cercanias de la Plaza de Alicante. Se trataba de don Benito Arques, que había ocupado cargos en la ciudad y sería regidor desde febrero de 1709 (56). Debido a la tardía recuperación de la plaza alicantina, las confiscaciones que efectuó se compusieron de bienes muebles y semovientes (57). 
El propósito manifestado por el Gobierno, vía Audiencia, fue que los bienes confiscados se aplicarían a remunerar las pérdidas de los vecinos y la reconstrucción de las ruinas. El enviado para ese fin fue el Oidor de la Audiencia, don Tomás Melgarejo y Gamboa, encargado asimismo de cuidar que el gobierno municipal se organizase de acuerdo con las leyes de Castilla(58). Tras siete meses de trabajo, envió un detallado informe al Consejo de Castilla, para su aprobación, que mereció los elogios de Ronquillo(59).

La misión de Melgarejo como Juez Privativo tenía como objeto:

a) Proceder a determinar los sujetos que permanecieron fieles a Felipe $\mathrm{V}$ y elaborar relaciones justificadas de las pérdidas sufridas diferenciando entre pérdidas y rentas dejadas de percibir.

b) Determinar el número de disidentes para llevar a cabo las confiscaciones previo examen, tasación y expresión de las cargas. Quedaba a su cargo también la declaración de las obligaciones de justicia que correspondian a cada partida confiscada.

c) Aplicar el producto de las confiscaciones a la remuneración de las pérdidas, satisfacción de mercedes y el entendimiento judicial en las tercerías impuestas, así como procurar que el volumen confiscado rindiese de inmediato los mayores beneficios poniéndolos en arriendo.

Siguiendo las instrucciones emanadas del Consejo, publicó los edictos emplazando a los afectados a justificar la fidelidad y pérdidas. Por lo que sabemos, parece que fue D'Asfeld el que propuso a Felipe $V$ la demostración documental de la fidelidad(60). El informe de Melgarejo resalta el hecho de que, en gran parte, las justificaciones se hicieron mediante las declaraciones de testigos, situación que promovió la precaución del funcionario(61). Baste decir que, en algunos casos, especialmente los comerciantes, pretendieron hacerlas mediante los propios libros de contabilidad. Para intentar precisar en lo posible su verdadero alcance, Melgarejo se valió de los informes que, bajo juramento, le proporcionaron hombres allegados a la vida pública y comercial de la ciudad y, naturalmente, libres de toda sospecha de desafección.

Las relaciones de pérdidas tienen gran interés, ya que se especifican las profesiones de los individuos, lo que, lamentablemente, no sucede en el caso de los considerados disidentes ni en el de los confiscados. Comprende 274 nombres, sin incluir al gremio de pescadores, franceses residentes, clero y algunas damas notables que fueron consignadas en relaciones independientes. Si bien son datos a manejar con precaución, pueden resultar indicativos del estado de rentas de los diferentes sectores sociales de la Gobernación y aportar luz sobre la composición social de los bandos en lucha. Si el carácter antiseñorial es perfectamente evidente en el caso de la Marina(62), la condición realenga de la mayor parte de las tierras alicantinas y el carácter cosmopolita 
de la cabeza de la Gobernación(63) no explican por sí mismas la inclinación de la población, y en particular de las clases acomodadas, en favor de uno u otro contendiente. De hecho, la necesidad de comarcalizar el problema se vuelve a plantear tras las aportaciones de Ruiz sobre la ausencia de un contenido claramente antiseñorial en Elche ${ }^{(64)}$ o en el de Orihuela(65). El sentimiento antifrancés, producto de la peculiar posición de éstos en la vida de la ciudad, junto a la exaltación producida por los acontecimientos de 1691; elementos de milenarismo social, afán de medro en algunos de los personajes más destacados; temor a los sitiadores campesinos de 1706; acoplamiento tras la ocupación militar en regla por parte de los aliados, son los factores que, junto a la mayor o menor presencia de fuerzas militares, aparecen en la documentación que hemos podido consultar. Sólo tras numerosas dificultades burocráticas surgidas entre los regidores y la corte, son detectables manifestaciones de añoranza por el régimen jurídico perdido(66).

De los 274 nombres relacionados, 150 (el 55,10\%) no pueden demostrar pérdidas, bien por ser jóvenes de apellidos ilustres que aún no han entrado en posesión del patrimonio familiar, por fallecimiento en algún caso y, generalmente, como se demuestra por la relación por oficios, porque no tenian mucho que perder. De estas personas, 24 (el $8,75 \%$ de los peticionarios) justificaron pérdidas por valor de 62.171 escudos de plata (el $62,20 \%$ de las pérdidas estimadas). De ellos tan sólo dos aparecen ligados a actividades comerciales, siendo los demás pertenecientes a la nobleza local con cargos administrativos y militares. Será este último grupo el que justifique mayores rentas dejadas de percibir. Destacan el Marqués del Bosch con 4.079 escudos de pérdidas y 2.074 escudos, respectivamente. En cuanto a las profesiones, aparecen reseñados como mercaderes 14 individuos con pérdidas de $7.344 ; 10$ tratantes con 4.579 escudos; ocho canteros, 220; un arriero, 50; cinco esparteros, 100; un albéitar, 340; dos zapateros, 170; tres marinos, 450; cuatro cirujanos, 500; dos médicos, 100; un cordelero, 100; un carretero, 200; dos ayudantes, 1.230; tres capitanes, 177. No justifican pérdidas, un sombrerero, un peluquero, dos confiteros, un sedero, un chocolatero, un salmero, un atunero y un blanquero. Aparecen 37 miembros de la nobleza local y 51 franceses, de los que 17 son reseñados como comerciantes y otro como tratante, justificando pérdidas por valor de 17.457 escudos $(67)$.

La lista de disidentes hecha por Melgarejo, entendiendo como tales a los que habian abandonado la ciudad ante la amenaza de recuperación por las armas realistas, comprende 344 nombres, de los que 309 corresponden a la ciudad, 10 a Muchamiel, 20 a San Juan y sólo cinco al lugar de Agost. El procedimiento seguido por el juez para determinar las confiscaciones puede resumirse en:

a) Averiguación de los que abandonaron la ciudad. 
b) Supuesta la huida y disidencia, se publican los edictos y pregones conminando a justificar la fidelidad.

c) El 7 de marzo de 1709 se procedió a la acusación formal y condena en rebeldía, como reos del delito de "lessa magestad" en primer grado y, en consecuencia, a la pena capital, reservando el modo y forma para cuando fueran apresados, así como a la confiscación de sus bienes.

d) Con el auxilio de técnicos nombrados por el Cabildo municipal, se pasó a la determinación de los bienes.

La lista de confiscados se compone de 165 nombres y supone un producto bruto total de 762.068 escudos de plata, descontando 90.092 escudos y 18 sueldos en concepto de cargas, tercerlas y obligaciones. Tras agregar posteriormente algunos efectos más, el saldo neto seria de 674.676 escudos y 9 sueldos.

Con el fin de proporcionar ingresos al fisco, se encargó a don Bernardo Bertolón el arrendamiento de las heredades y tierras. Los arrendamientos se hicieron rápidamente en el caso de las mejores tierras, tras solucionar algunos problemas derivados del choque de jurisdicciones entre las autoridades ${ }^{(68)}$.

El reconocimiento de los censos que respondían los disidentes, en cuanto pasaban a ser deudas de la Hacienda, exigía la presentación de los documentos del "carregament". En cuanto a los censos acreedores, la acreditación ofrecia grandes dificultades por razones obvias, salvo en el caso de los que respondian diferentes villas y lugares. Sin embargo, la principal preocupación de Melgarejo era la del carácter jurídico de los bienes confiscados, que, en su mayor parte, estaban sujetos a vínculos de mayorazgo(69).

En cuanto a los bienes de eclesiásticos, no hubo problemas en Alicante, ya que fue el Juez del Breve Apostólico el que se hizo cargo de los clérigos disidentes, juzgando Melgarejo que su volumen era bastante para el reemplazo de las pérdidas sufridas por las iglesias y los eclesiásticos.

Una Resolución del Consejo vino a poner en claro, finalmente, las insuficiencias del decreto de 11-I-1709, al disponer que se pasara a hacer las asignaciones de forma inmediata a aquellos que, durante la ocupación aliada, se refugiaron en territorio realista. Pero en caso de aparecer los dueñosantes de trascurrido el año de las sentencias y justificaran su fidelidad, les deberian ser reintegradas las propiedades, quedando a su cargo el pago de todas las mejoras que los nuevos tenedores hubiesen hecho. En cuanto al carácter jurídico, no se debía diferenciar entre bienes libres y de mayorazgo urespecto de quedar salbos los derechos de terceros y ser est causa pp. ccan(70).

Asi, pues, el funcionario comenzó a hacer las asignaciones correspondientes a las pérdidas y a algunas mercedes expresamente asignadas 
sobre Alicante(71). Evaluar el volumen de concesiones hechas en remuneración de pérdidas con exactitud es difícil, ya que carecemos de los documentos notariales de Melgarejo, siendo sólo posible una aproximación a partir del volumen bruto, las pérdidas declaradas, las diferentes asignaciones de mercedes y el volumen del remanente. A pesar de que el Consejo fue explícito al señalar que el remanente de las adjudicaciones debía dedicarse a las obras necesarias en la ciudad(72), no fue hasta ocho años más tarde cuando el remanente pasó a manos de los regidores alicantinos(73).

La labor de Corsiniani se desarrolla a partir de un R. Despacho de 11 de abril de 1713 que confirmaba un R. Decreto de 22 de septiembre del año anterior. Al tiempo que elevaba al cargo de Juez Privativo al hasta entonces Subdelegado, Juan D. Corsiniani, se disponía que los bienes que aún quedaban se repartiesen de la forma siguiente:

a) Condonación a la ciudad de los censos y censales que respondía a disidentes con todos sus réditos vencidos.

b) Concesión de una casa como ayuntamiento provisional.

c) Adjudicación al gremio de pescadores del producto de la venta de una heredad.

d) La liquidación de las pérdidas de la Colegial, iglesias y comunidades religiosas.

e) Procurar alivio a los pobres y viudas.

f) Adjudicación del remanente a la ciudad.

Corsiniani, alegando la cortedad de los haberes(74), tardó cinco años en hacer entrega del remanente a las autoridades municipales, que, finalmente, elevaron un pedimento formal al respecto(75). El 20 de agosto de 1717 hacía entrega de estos bienes para que «... como de propios los goce, posea y usufructue desde hoy día de la fecha en adelante» (76).

\section{VI._-La administración por la ciudad.}

El remanente lo desglosamos para su análisis en las tres partidas básicas: tierras, propiedades urbanas y censos. Comprende la casi totalidad de los bienes de 68 de los 165 confiscados. Las tierras se estimaron en un total de 67.798 pesos, 3 sueldos y 9 dineros, de los que 8.850 correspondian a la valoración del agua y 631 pesos a los bienes muebles de las heredades.

La propiedad urbana ascendía a un total de 79.580 pesos y 2 sueldos, de los que 76.115 pesos y 5 sueldos correspondian a la ciudad de Alicante,694 al lugar de San Juan, 1.350 a Monforte, 60 a Agost y 1.230 pesos y 17 sueldos a diferentes lugares de la Gobernación. 
El capital censal se dividia en:

a) Censos condonados a la ciudad por un capital de 75.790 pesos, 5 sueldos y 6 dineros.

b) Censos respondidos por diferentes lugares de la Hoya de Castalla por un total de 28.151 pesos y 14 sueldos.

c) Censos adjudicados para después de la muerte de diferentes personas que se satisfacian de estos fondos en concepto de cargas de justicia por 4.712 libras.

El análisis de las propiedades rústicas y urbanas parece indicar que el acento de las confiscaciones se puso sobre aquellos a los que algo se les podia confiscar, ya que es reducido el número de propietarios con bienes de escasa entidad. En varios casos un solo titular tiene buen número de construcciones urbanas. Así, por ejemplo, Gaspar Castillo tenía 12 casas y solares valorados en 6.856 libras y 2 sueldos (77).

Una R. Provisión de 24 de marzo de $1718(78)$ disponía, ante las reiteradas peticiones de la ciudad que, la mitad de los frutos y rentas que produjeran los bienes confiscados se destinase al pago de los abastecimientos hechos ante la amenaza aliada. La otra mitad debe dedicarse a las obras de reconstrucción a que en principio fue asignada.

La forma de explotación por parte del Cabildo, que en vano trató de hacer posible la enajenación a excepción de algunas de escasa entidad realizadas a censo, fue el arriendo. Cuando los bienes estuvieron en manos de Bertolón, los arriendos se hicieron por la mitad de los frutos recogidos, estando ocupadas las tierras hasta 1717 , excepto algunas partidas pequeñas por uno haberse encontrado persona alguna que entrase en ellos por su escasa entidad (79). Asi, entre 1715 y 1717 , en que los arrendamientos corrieron a cargo de Corsiniani, arrojaron unos ingresos de 1.920 pesos y 27 sueldos. El 77,77 por ciento de esta cantidad procedía de las tierras y heredades.

A finales de agosto de 1717 los regidores acordaron pregonar nuevos arrendamientos siguiendo el procedimiento habitual para las posturas (81). Las condiciones de la ciudad eran, en cuanto a tiempo, de dos años en firme y dos voluntarios. El precio dependía de las pujas realizadas, desechando las demasiado bajas. Las obras y mejoras correrian a cargo de la misma ciudad.

Según los balances finales de la contabilidad municipal, los ingresos y gastos entre 1717 y 1725 fueron: 
"Sumario General del Cargo Lexitino arreglado a los testimonios de la Ciudad"

\begin{tabular}{|c|c|c|}
\hline LIBRAS & SUELDOS & DINEROS \\
\hline 810 & - & 2 \\
\hline 779 & 10 & - \\
\hline 1.639 & 1 & - \\
\hline 1.676 & 17 & 4 \\
\hline 1.785 & 4 & 4 \\
\hline 2.674 & 2 & 5 \\
\hline 1.866 & 5 & - \\
\hline 2.160 & 16 & 10 \\
\hline 2.187 & 15 & 7 \\
\hline 15.579 & 12 & 8 \\
\hline
\end{tabular}

"Datta Genl. desde el año 1718 hasta el fin de Oct." de 1725"

Prorrata de $1717 \ldots \ldots$.

Año de 1718

$» 11719 \ldots \ldots \ldots$.

$" \quad 1720 \ldots \ldots \ldots$.

$" m 1721 \ldots \ldots \ldots$

$" \quad 1722 \ldots \ldots \ldots$

n

1723

" 1724

$» 1725 \ldots \ldots \ldots$.

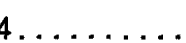

\section{Datta Genl. desde el ano 1718 hasta el fin de Octio de 1725}

\begin{tabular}{|c|c|c|c|}
\hline & LIBRAS & SUELDOS & DINEROS \\
\hline Prorrata de 1717 & - & - & - \\
\hline Año de $1718 \ldots \ldots \ldots$ & 228 & - & - \\
\hline$" 》 1719 \ldots \ldots \ldots$ & 856 & 4 & 8 \\
\hline$" » 1720 \ldots \ldots \ldots$ & 973 & 18 & 11 \\
\hline$" n 1721 \ldots \ldots \ldots$ & 842 & 15 & 2 \\
\hline$" \quad " 1722 \ldots \ldots \ldots$ & 1.280 & 12 & 11 \\
\hline$" » 1723 \ldots \ldots \ldots$ & 1.616 & 18 & 11 \\
\hline$n \quad n 1724 \ldots$ & 1.280 & 18 & . 11 \\
\hline \multirow[t]{2}{*}{ Prorrata de $1725 \ldots \ldots$} & 5.855 & 15 & 6 \\
\hline & 12.876 & 14 & $\langle 83$ \\
\hline
\end{tabular}


La Paz de Viena, en su artículo IX, se refería al perdón de los partidarios de uno y otro bando y a la devolución de los bienes confiscados. El proceso de reintegración de los bienes adjudicados a la ciudad a sus antiguos propietarios fue casi total, aunque subsistieron algunos efectos en la administración municipal.

A nivel general, puede concluirse que el objeto fundamental de las confiscaciones tuvo, en un sentido político, la misión de castigar la infidelidad. Por otra parte, se convirtio en un instrumento para afianzar las regalias de la Corona frente a los poderes nobiliarios. Las derivaciones que podian suponer un precedente peligroso para los privilegios de la aristocracia - por ejemplo, la reversibilidad a la Corona que defendía Macanaz- fueron eliminadas, convirtiéndose en meras anécdotas personales. Si los ingresos líquidos para la Hacienda no fueron cuantiosos, entre otras cosas debido a las cargas propias a que estaban sujetos y a las de justicia que les fueron asignadas, los bienes confiscados permitieron premiar a los que permanecieron fieles a Felipe V. En todo caso, no parece que hubiera un grado de represión personal equiparable a la que Garcia Carcel señala para el caso de las Germanías, ni aun en los casos de Játiva y Denia. En el de Alicante, la mayor parte del volumen confiscado procede de miembros de las clases pudientes. La decisión de aplicar el producto de las confiscaciones en la misma Gobernación hizo que, a menudo, revirtieran casi integramente en las mismas clases sociales. Una simple ojeada a la intrincada red de parentelas de la nobleza local pone de manifiesto que, en ocasiones, las remuneraciones en concepto de reparaciones por pérdidas de guerra fuesen a parar a ramas colaterales de las mismas familias confiscadas. En definitiva, la represión no se condujo por la vía de la violencia personal, salvo, claro está, en los acontecimientos militares de plena guerra. Los cambios se produjeron por via del cambio constitucional y administrativo. 


\section{NOTAS:}

(1) P. Ejem. BORRUL Y VILLANOVA, F. J. Fidelidad de la Ciudad y Reino de Valencia en tiempos de las guerras que empezaron en el año de 1705. Valencia. 1810.

(2) REGLA, J. Aproximaçió a la Historia del País Valencià. Valencia. 1978 (1.a ed. 1968).

(3) PEREZ APARICIO, C. "La Guerra de Sucesión en el P. V.". SPICEU. Valencia. 1978. "La Guerra de Succesio: Una revolució camperolan. I Congreso de Historia del P. V. (1976), vol. III. 511-524. "El austracismo en Valencia; un nuevo intento de sublevación en 1710 . Estudis, $n{ }^{\circ} 4$. Valencia (1975). Del Alçament Maulet al triomf botifler. Valencia. 1981. Remite a otros articulos sobre sanidad, unlversidad, precios, etc., de la misma época.

(4) KAMEN, H. La Guerra de Sucesión en España (1700-1715). Barcelona. 1974.

(5) KAMEN, H. La España de Carlos II. Barcelona. 1981, p. 21, n. 39.

(6) RUIZ TORRES, P. Señores y propietarios. Cambio social en el sur del P. V. 1650-1850. Valencia. 1981, pp. 159-185.

(7) GIMENEZ LOPEZ, E. Alicante en el siglo XVIII. Economia de una ciudad portuaria en el Antiguo Régimen. Valencia. 1981, pp. 19-33.

(8) MiÑANA, J. M. De Bello Rustico Valentino. Trad. de Vicente Castañeda en Revue Hispanique, LV. (1922), pp. 447-618. BELANDO, N. J. Historia Civil de España. Sucesos de la Guerra y Tratados de Paz... 3 vol. Madrid. 1740-44, BACCALLAR Y SANNA, MARQUES DE SAN FELIPE. Comentarios de la Guerra de España e historia de su Rey Felipe V, el Animoso: Madrid. 1957. ORTI Y MAYOR, J. V. Diario de lo sucedido en la Ciudad de Valencia desde el dia 3 de octubre... B. U. V. Mss. 460. FELIU DE LA PEÑA Y FARREL, N. Anales de Cataluña y ep/logo breve de los progresos y famosos hechos de la Nación Catalana. 3 vol. Barcelona, 1709. PERALES, J. Historia de la... Ciudad y Reino de Valencia. Madrid. 1880.

(9) MIÑANA. Op. cit., III-3, III-20. PEREZ, Del Alçament..., pp. 81-90. KAMEN, La Guerra..., pp. 295-329, etc.

(10) PESET REIG, M. "Apuntes sobre la abolición de los fueros y la Nueva Planta». I Congreso de $H^{2}$ del P. V. Vol. III, pp. 525-536.

(11) PEREZ. Del Algament.., p. 128. MIÑANA. Op. cit., II. 11.

(12) MIÑANA. Op. cit., III-20.

(13) PEREZ. Del Alçament..., pp. 113-26. KAMEN. La Guerra..., 337 y ss.

(14) MIÑANA. Op. cit., III-4.

(15) A. H. N. Consejos. Lib. 1475, 34, f. 74.

(16) R. D. 30-V-1707. Consejos Suprimidos. Leg. 18. 190. KAMEN, La Guerra..., 337-338.

(17) R. D. 5-X-1707. LAFUENTE, M. $H^{2}$ General de España. Vol XVIII, p. 202, n. 3. MARTIN GAITE, C. Macanaz, otro paciente de la Inquisicion. Barcelona. 1982, p. 116.

(18) A. H. N. Estado, leg. 331.

(19) Idem.

(20) Idem.

(21) KAMEN, La Guerra..., p. 355.

(22) A. H. N. Consejos, leg. 6, 806, A, nº 151.

(23) A. H. N. Estado, leg. 188. 16-IV-1707.

(24) A. H. N. Estado, leg. 188. Grimaldo-Milán de Aragón. 27-IV-1707.

(25) KAMEN. Op. cit., 357. Recoge la opinión de Bourke al respecto.

(26) Idem, pp. 358.

(27) A. M. A. Al. 1, lib. 25, f. 389-40.

(28) A. H. N. Estado, leg. 2.973.

(29) KAMEN, Op. cit., p. 355. 
(30) A. H. N. Estado, leg. 2.973.

(31) Idem.

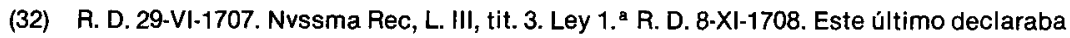
a la Iglesia no incursa en el delito de rebelión.

(33) KAMEN. Op. cit., 341-346. MARTIN GAITE. Op. cit., 116-42.

(34) Vid. cit. 32.

(35) R. D. 27-XI-1707.

(36) Apud MARTIN GAITE, Op. cit., pp. 123-124.

(37) VOLTES BOU, P. La Guerra de sucesión en Valencia. Valencia. 1964, pp. 189-90.

(38) A. H. N. Estado, leg. 345. "Relación de los eclesiásticos...". MARTIN GAITE. Op. cit., p. 130 y ss.

(39) MARTIN GAITE. Op. cit., pp. 133-137.

(40) KAMEN. Op. cit., p. 344, se refiere a la documentación de Macanaz. Según el Juez de Confiscaciones le fue recogida por $R$. Cepeda. Ni PEREZ, ni GAITE hacen referencia a la existencia de estos documentos.

(41) MARTIN GAITE. Op. cit., pp. 116-82. KAMEN, Op. cit., pp. 341-46.

(42) Macanaz publico un bando enviado por Grimaldo al efecto. MARTIN GAITE. Op. cit., 139.

(43) DOMINGUEZ ORTIZ. Sociedad y Estado..., pp. 18-19. KAMEN. La España..., pp. 370420; La Guerra..., pp. 99-136.

(44) KAMEN. Op. cit., p. 106.

(45) MAURA Y GAMAZO. Carlos // y su Corte. 2 vols. Madrid. 1911.

(46) A. H. N. Estado, leg. 2.973. "Parecer del P. Confesor".

(47) PEREZ APARICIO. "La Guerra de Successió...".

(48) MIÑANA. Op. cit., 1-5.

(49) A. H. N. Estado, leg. 2.973.

(50) A. H. N. Consejos, leg. $6.085, n .{ }^{\circ} 152$.

(51) Sobre Ronquilio, MARTIN GAITE. Op. cit., p. 130. SAN FELIPE, Comentarios..., se refiere a él como ex corregidor de Madrid en p. 7 y nuevamente corregidor ante las alteraciones populares por el alza de precios, con Carlos II. Idem, p. 8. Una descripción de carácter y un juicio sobre lo poco que "les salió la cuentan a los franceses con su nombramiento para la presidencia del Consejo en 1705. Idem, 85.

(52) DOMINGUEZ ORTIZ: Op. cit., p. 92.

(53) MALDONADO MACANAZ, J. Melchor de Macanaz. Testamento Politico. Pedimento fiscal. Madrid, 1972, pp. 76-77 y 194. A. H. N. Estado, leg. 2.973. uInforme de Macanaz sobre las confiscaciones...".

(54) DOMINGUEZ ORTIZ. Op. cit., cap. "El prerreformismo borbónico», pp. 84 y ss.

(55) A. H. N. Estado, leg. 350. Macanaz-Grimaldo. 9-XII-1708.

(56) A. M. A. Al. 16 , leg. $3, n^{\circ} 31$.

(57) A. H. N. Consejos, leg. 6.085, n. ${ }^{\circ} 152$.

(58) R. D. 31-XII-1708. A. H. N. Estado, leg. 350 . A. M. A. Al. 2, lib. 20, f. 154 y lib. 25, f. 147 y ss.

(59) A. H. N. Estado, 367. Ronquillo-Grimaldo. 18-VII-1709.

(60) A. H. N. Estado, leg. 345. D'Asfeld-Felipe V. 6-III-1707.

(61) A. H. N. Consejos, leg. $6.805, n^{\circ} 152$.

(62) . PEREZ. "La Guerra de Successió...".

(63) GIMENEZ LOPEZ. Op. cit., recoge las consecuencias de la guerra en Alicante.

(64) RUIZ TORRES. Op. cit., p. 171. 
(65) PARDO Y MANUEL DE VILLENA, A. El Marqués de Rafal y el levantamiento de Orihuela en la Guerra de Sucesión (1706). Madrid. 1910.

(66) VIRAVENS PASTOR, V. Crónica de... la Ciudad de Alicante. Alicante, 1876. MALTES, J. B. llice llustrada. Alicante 1907. A. H. N. Estado, leg. 190.

(67) POITRENAU, A. "La inmigración francesa en el reino de Valencia (siglos XVI-XIX). Moneda y Crédito, n. ${ }^{\circ} 137$ (1976), pp. 103-134. GIMENEZ LOPEZ. Op. cit., pp. 63-70, 195-199 y 237-255.

(68) A. H. N. Consejos, leg. $6.806, n^{\circ} 48$.

(69) A. H. N. Consejos, 6.085, n. $^{\circ} 152$.

(70) Idem y A. M. A. Al. 2, lib. 20, f. 154. El plazo era de un año a partir de la sentencia.

(71) Varios sujetos de Alicante aparecen relacionados en las listas de mercedes concedidas. A. H. N. Estado, leg. 331.

(72) A. H. N. Consejos, $6.085, n .{ }^{\circ} 233$.

(73) A. M. A. Al. 2, lib. 25, ff. 356-362.

(74) A. M. A. Al. 2, lib. 19, f. 190.

(75) A. M. A. Al. 9, lib. 7. 18-VII-1717.

(76) A. M. A. Al. 2, lib. 19, f. 191.

(77) A. M. A. Al. 2, lib. 20.

(78) R. D. 24-IIl-1718. A. M. A. Al. 2, lib. 20, f. 166.

(79) A. H. N. Consejos, leg. 6.085, n. ${ }^{\circ} 152$.

(80) A. M. A. Al. 2, lib. 20, f. 183.

(81) A. M. A. Al. 2, lib. 21. 27-VIII-1717.

(82) A. M. A. Al. 13, leg. 78.

(83) Idem. 